\title{
Role of IgG Plasma Cells in the Change of Protein C System in Ulcerative Colitis
}

Received: June 12, 2017; Accepted: June 25, 2017; Published: June 29, 2017

\section{Letter to Editor}

Ulcerative colitis (UC), one type of inflammatory bowel disease, often involving part or all of the colon segment, and the damage generally confined to the colon mucosa [1]. Our previous experimental results indicated that the imbalance of regulatory function of protein C system (PCS) may be one of the most important pathogenesis in the patients with UC. Macrophages from colonic mucosa act on the mucous microvascular endothelial cells through secretion of proinflammatory cytokines, and further causing the inhibition of PCS [2]. While the initiator of PCS inhibition by macrophages is still unclear.

Overactivation of humoral immunity is closely related to UC pathogenesis process [3], and lamina propria lymphocytes (mainly activated $B$ lymphocytes) are suggested to be the source of increased immunoglobulin and antibody [4]. Our research revealed that plenty of plasma cells accumulated in the colonic mucosa in UC mice, flow cytometry experiments further confirmed the infiltration of $\mathrm{CD} 54^{+} \mathrm{CD} 38^{+}$plasma cells, and the phenotype of the plasma cells was IgG type. These results are consistent with the recent studies which draw the conclusion that the number of IgG type plasma cells was elevated in the inflammatory tissues of some autoimmune diseases [5]. The above results indicate that the number of IgG plasma cells is related to the disease activity and play an important role in the pathological process of UC.

Next, we explore if the elevated plasma cells associated with macrophages -induced PCS change. Our earlier experiment also found infiltration of excess macrophages [2], as well as enhancement of IgG immune complexes (IgG-IC) in UC (unpublished), meanwhile, some studies indicated that CXCR4 ${ }^{+}$ IgG plasma cells result in the pathological process of UC through CD14 ${ }^{+}$macrophages stimulated by FcyRs [5]. In order to explore how increased IgG plasma cells act on macrophages, and whether the elevated IgG-IC mediate the interaction of plasma cells with macrophages, IgG-IC was mimicked in vitro to simulate isolated colon macrophages, and the expressions and levels of proinflammatory cytokines such as TNF- $\alpha$ and IL- 6 in the supernatant of macrophages were detected. We found that both TNF- $\alpha$ and IL-6 expressions and levels were increased obviously. Therefore, we speculate that IgG plasma cells increase, and initiate the inhibition of PCS in the pathogenesis of UC, possibly by the secretion of IgG antibody, and formation of IgG-IC, further action on the macrophages. IgG type plasma cells might represent a promising target for the treatment of UC.

\author{
Lin $\mathrm{XH}^{1}$, Wang $\mathrm{HC}^{2 \#}$, Guo JL, \\ Yang JN ${ }^{1}$, Li YX ${ }^{1}$, Dai ZF ${ }^{1}$, \\ Yang RL ${ }^{1}$, Zhang J J ${ }^{4}$, \\ Yang $\mathrm{DS}^{5}$, Wang $\mathrm{B}^{1}$, $\mathrm{Hu} \mathrm{JH}^{4}$, \\ Ren $\mathrm{XQ}^{4}$ and Cheng $\mathrm{GC}^{3}$
}

1 Department of Clinical Laboratory, Translational Medicine Center, Huaihe Hospital Affiliated to Henan University, China

2 Department of Nephrology, First Affiliated Hospital of Henan University, China

3 Department of Cardiovascular Medicine, Huaihe Hospital Affiliated to Henan University, China

4 Department of General Surgery, Huaihe Hospital Affiliated to Henan University, China

5 Department of Gastroenterology, Huaihe Hospital Affiliated to Henan University, China

\# equally contributed

\section{Corresponding author: Ren XQ \\ Ixh@huaihe.com.cn}

Department of General Surgery, Huaihe Hospital Affiliated to Henan University, 115 Ximen Street, Kaifeng City, Henan Province, China.

Tel: 0086-371-23906758

Fax: 0086-371-23906058

Citation: Lin XH, Wang HC, Guo L, et al. Role of IgG Plasma Cells in the Change of Protein C System in Ulcerative Colitis. TransI Biomed. 2017, 8:2. 


\section{References}

1 Parmar AR, Trivedi PP, Jena GB (2014) Dextran sulfate sodiuminduced ulcerative colitis leads to testicular toxicity in mice: Role of inflammation, oxidative stress and DNA damage. Reproductive Toxicology 49: 171-184.

2 Lin XH, Wang HC, Wei DD, Wang B, Ge QX, et al. (2015) Study of the change and role of protein $C$ system in ulcerate colitis. Sheng Li Xue Bao 67: 214-224.
3 Jinno Y, Ohtani H, Nakamura S, Oki M, Maeda K, et al. (2006) Infiltration of CD19+ plasma cells with frequent labeling of Ki-67 in corticosteroidresistant active ulcerative colitis. Virchows Arch 448: 412-421.

4 Yacyshyn BR (1993) Activated CD19+ B cell lamina propria lymphocytes in ulcerative colitis. Immunol Cell Biol 71: 265-274.

5 Uo M, Hisamatsu T, Miyoshi J, Kaito D, Yoneno K, et al. (2013) Mucosal CXCR4+ IgG plasma cells contribute to the pathogenesis of human ulcerative colitis through FcgammaR-mediated CD14 macrophage activation. Gut 62: 1734-1744. 